\title{
Besides Sarcopenia, Pre-Sarcopenia Also Predicts All-Cause Mortality in Older Chileans
}

This article was published in the following Dove Press journal:

Clinical Interventions in Aging

\author{
Lydia Lera (1D) 1,2 \\ Bárbara Angel (D) \\ Carlos Marquez (D) \\ Rodrigo Saguez $\mathbb{D}^{1}$ \\ Cecilia Albala $\mathbb{D}^{\prime}$ \\ 'Public Health Nutrition Unit, Institute of \\ Nutrition and Food Technology, \\ University of Chile, Santiago, Chile; ${ }^{2}$ Latin \\ Division, Keiser University eCampus, \\ Fort Lauderdale, FL, USA
}

Correspondence: Cecilia Albala; Lydia Lera Public Health Nutrition Unit, Institute of Nutrition and Food Technology, University of Chile, El Líbano 5524, Santiago, 7830490, Chile

Tel +5622978I 455 ;

$\mathrm{Tel}+56229781537$

Email calbala@uchile.cl; llera@inta.uchile.cl
Purpose: Many studies have demonstrated that Sarcopenia causes a serious impact on health, including death in older adults. The objective of this study was to determine the association of sarcopenia and pre-sarcopenia with all-cause mortality in older Chileans.

Subjects and Methods: Follow-up of 2311 community-dwelling people $\geq 60 \mathrm{y}$ from the Alexandros cohort. Anthropometric measurements, handgrip strength, mobility, and physical performance tests were performed. Sarcopenia, pre-sarcopenia, and severe sarcopenia were defined using the 2010 European Working Group on Sarcopenia in Older People (EWGSOP1) algorithm. Muscle mass was estimated using a prediction model with cut-off points validated for the Chilean population. Physical performance was determined by $3 \mathrm{~m}$ walking speed or five chair-stands or time up go test (TUG). Mortality data were obtained from death certificates of the National Civil Registry. Life tables for survival data, Kaplan Meier estimations, and Cox regression were calculated.

Results: The prevalence of sarcopenia was $20.2 \%$ (95\% CI: $18.6 \%$ to $21.9 \%$ ) and similar in both sexes; pre-sarcopenia was identified in $20.4 \%$ (95\% CI: $18.8 \%$ to $22.1 \%$ ) of the sample. Kaplan Meier survival estimates demonstrated lower survival rates for the people with sarcopenia and pre-sarcopenia (Log rank test for equality of survivor functions: $p<0.0001$ ). A dose-response was observed in the survival rates according to the stages of sarcopenia, showing the lowest survival rates for the people with severe sarcopenia, followed by older adults with sarcopenia, pre-sarcopenia, and without sarcopenia (Log rank test for equality of survivor functions: $\mathrm{p}<0.0001$ ). After adjusting for age, sex, nutritional status, and number of chronic diseases, hazard ratios for death showed higher risk for subjects with sarcopenia $(\mathrm{HR}=1.47,95 \% \mathrm{CI}: 1.17-1.83)$ and pre-sarcopenia $(\mathrm{HR}=1.35,95 \% \mathrm{CI}: 1.03-1.78)$ in comparison with people without sarcopenia.

Conclusion: The results confirm a dose-response increase in the risk of all-cause death in older adults with sarcopenia and pre-sarcopenia compared to non-sarcopenic individuals.

Keywords: cohort study, survival probability, predictive models, skeletal muscle mass

\section{Introduction}

Many studies have demonstrated that sarcopenia causes a serious impact on health, including death in older adults. The loss of mass and function that defines sarcopenia $^{1}$ is related to loss of function, dependency, falls, decreased immunity, ${ }^{2-5}$ increased risk of osteoporosis, ${ }^{6}$ frailty, hospitalization, poor quality of life, and mortality, ${ }^{7-12}$ thus producing a high burden of disease.

Although there is not a consensus on the operational definition of sarcopenia, the most widely used is that developed in 2010 by The European Working Group of Sarcopenia in Older People (EWGSOP1). ${ }^{2}$ The EWGSOP1 defines sarcopenic submit your manuscript DovePress in 口 
individuals to have low muscle mass in addition to low muscle strength or low physical performance. The consensus also defines a pre-state of sarcopenia termed "presarcopenia" when the sole characteristic present is low muscle mass. The diagnostic algorithm proposes physical performance as the primary variable, represented by gait speed, followed by the evaluation of muscle strength and mass. The revised version (EWGSOP2) ${ }^{13}$ uses the same variables, but the diagnostic algorithm proposes low muscle strength as primary variable, followed by measurement of physical performance and muscle mass.

The progressive age-related loss of muscle mass is the main risk factor for sarcopenia, leading to an increasing prevalence of this condition as the population ages. Chile is aging quickly and is among the three countries with the highest life expectancy in the Americas, ${ }^{14}$ increasing the prevalence of sarcopenia. Using the EWGSOP1 definition, the prevalence of sarcopenia in Chile is $19 \%$, similar in men and women, and reaches $30 \%$ in people 80 years and older. ${ }^{15}$ In the same study, pre-sarcopenia was identified in $6.5 \%$ of the total sample, similar in men and women. Studies done in Latin America with the same diagnostic algorithm have shown that the prevalence of sarcopenia fluctuates between $13.9 \%$ in two cities of Brazil, ${ }^{16} 11.5 \%$ in Bogotá, Colombia ${ }^{17}$ and $9.9 \%$ in Mexico, ${ }^{18}$ although none of these studies report the prevalence of presarcopenia.

Several authors have shown that the survival rate of sarcopenic people is lower than that of non-sarcopenic subjects $^{10,12,19-22}$ however the effects of pre-sarcopenia on survival have not been studied.

The change in the diagnostic algorithm (EWGSOP2) does not consider the pre-sarcopenic state as important in determining if this condition is also a risk factor for survival. The objective of this study is to determine if sarcopenia, as identified with the EWGSOP1 diagnostic algorithm, ${ }^{2}$ is associated with all-cause mortality in a follow-up of a large cohort of community-dwelling older adults, and to explore if pre-sarcopenia is also a risk factor for survival.

\section{Subjects and Methods Study Population}

Follow-up of 2311 community-dwelling people 60 years and older (mean \pm SD: $69.2 \pm 6.9$ years; $67.3 \%$ female) followed between 5 and 15 years, from the Alexandros longitudinal study, designed to investigate disability associated with obesity, previously described. ${ }^{23}$ In brief, ALEXANDROS is a longitudinal study conducted in Santiago, Chile, which includes the follow-up of three cohorts: 1) the original SABE sample15 composed of 1173 people 60 years and older, born before 1940 and recruited in 1999-2000 through a probabilistic sampling process; 2) the ALEXANDROS cohort composed of 950 people born between 1940 and 1948 recruited in 2005-2008, randomly selected from the primary health care center (PHCC) registries (where $85 \%$ of the older adults are registered) in a two-step procedure, health care centers and registered older adults from the selected PHCC; and 3) the Pension Health Institutions (ISAPRES) cohort of 266 people of high socioeconomic level born before 1948 and randomly selected from private health insurance system registries (ISAPRES) recruited in 2005, in Santiago, Chile. The participants underwent faceto-face interviews including self-reported chronic diseases (hypertension, diabetes, cancer, COPD, stroke) and selfperceived symptoms of depression, as measured by the Short Form of the Geriatric Depression Scale (GDS-15). Anthropometric measurements, handgrip strength, mobility, and physical performance tests were performed as previously described. ${ }^{24}$ Skeletal muscle mass index (SMI) was calculated as the ratio of appendicular skeletal muscle mass (ASM) and height ${ }^{2}\left(\mathrm{~kg} / \mathrm{m}^{2}\right)$. BMI was calculated as $\mathrm{kg} / \mathrm{m}^{2}$, and nutritional status was defined according to categories that have been employed for this age group in the previous research: ${ }^{25}$ underweight $(<20)$, normal weight (20-24.9), overweight (25-29.9), obesity $(\geq 30)$.

\section{Procedures}

Sarcopenia was defined using an adapted version of the EWGSOP $1^{2}$ with HTSMayor software. ${ }^{26}$ ASM was estimated with the following Chilean population prediction model: ${ }^{24}$

$\operatorname{ASM}(\mathrm{kg})=0.107$ (weight $)+0.251$ (knee-height $)+$ 0.197 (calf-circumference) +0.047 (dynamometry) -0.034 (hip-circumference) + 3.4178 (male) - 0.020 (age) - 7.646;

SMI was defined with cut-off points obtained by means of the prediction model presented above (men: $7.45 \mathrm{~kg} / \mathrm{m}^{2}$; women: $5.88 \mathrm{~kg} / \mathrm{m}^{2}$ ). ${ }^{27}$ Muscle strength was measured by handgrip dynamometry (Hand Dynamometer T-18, Country Technology, Inc.) and was also defined with cutoff points obtained for the Chilean population (men $27 \mathrm{~kg}$; $15 \mathrm{~kg}$ women). ${ }^{28}$ 
Physical performance was determined by three-meter walking speed, with a cut-off of $0.8 \mathrm{~m} / \mathrm{sec}$; for people missing this measurement, it was replaced by the speed in performing the timed up and go test (TUG). Stages of sarcopenia were determined by the classification suggested by the EWGSOP1: pre-sarcopenia (low muscle mass), sarcopenia (low muscle mass and either low muscle strength or low physical performance) and severe sarcopenia (low muscle mass, low muscle strength, and low physical performance). ${ }^{2}$

Information about all-cause mortality was available for each participant of the study, as mortality data were obtained from death certificates of the National Civil Registry until July 30,2017. There were 478 total deaths in the period under observation (196 men and 282 women).

\section{Statistical Analysis}

Summary measures were expressed as mean \pm standard deviation (SD), median, and inter-quartile range (IQR), or total number and percentage with $95 \%$ confidence intervals $(95 \% \mathrm{CI})$. The difference between genders was calculated by two-sample mean-comparison test or Pearson's Chi-squared test, depending on the distribution of the variables. Kaplan-Meier survival curves and probabilities of survival by sex were estimated according to stages of sarcopenia. Cox proportional regression models for 5-15 years' mortality were estimated to analyze crude and adjusted hazard ratios and $95 \%$ CI of death by the presence of pre-sarcopenia and sarcopenia (sarcopenia + severe sarcopenia). No violations of the proportional hazard's assumption were detected. The models included are unadjusted (model 1), adjusted for sex and age group (model 2), adjusted for sex, age group and obesity (model 3), adjusted for sex, age group, obesity, physical activity, and number of chronic diseases (model 4), and adjusted for sex, age group, obesity, physical activity, number of chronic diseases, and smoke habits (model 5). All statistical analyses were performed using STATA15 software (StataCorp.2015. Stata Statistical Software, Release 14. College Station, TX, StataCorp LP).

\section{Results}

Table 1 shows the socio-demographic and health characteristics of the study sample by sex. No differences between sexes were observed for the mean age (total $69.2 \pm 6.9$ years), nor for the following characteristics: the proportion of people in each age category, people living alone (total $10.0 \%$; 95\% CI: $8.8-11.3$ ), years of education (6y), or proportion of people with $>8$ years of education (total 40.4\%; 95\% CI: 38.3-42.5). The proportion of one or more limitations in Activities of Daily Living (ADL) was 12.8\% (95\% CI:11.5-14.2) and was similar in both men and women; the prevalence of one or more limitations in Instrumental Activities of Daily Living (IADL) however was significantly higher in men than in women ( $30.3 \%$ vs $25.9 \%, p=0.027)$. Low physical activity was higher in men than women $(\mathrm{p}<0.005)$. Three quarters of the sample reported no physical activity in the last three months and only 5\% reported practicing $\geq 5$ times/week. Women reported more chronic diseases than men $(\mathrm{p}<0.0001)$ and a lower proportion of smoking habits (30.7\% vs $46.6 \%$, respectively).

Table 2 displays anthropometric variables, body composition, handgrip strength, and physical performance. All anthropometrics measures were significantly higher in men than in women, except BMI $\left(27.3 \mathrm{~kg} / \mathrm{m}^{2}\right.$ vs $29.0 \mathrm{~kg} / \mathrm{m}^{2}$; respectively) and hip circumference $(101.7 \mathrm{~cm}$ vs $105.6 \mathrm{~cm}$, respectively). Regarding physical performance, women performed worse than men $(38.9 \%$ vs $27.8 \%$, $\mathrm{p}<0.0001$, respectively).

The prevalence of sarcopenia was $19.6 \%$ (95\% CI: $18.0 \%$ to $21.2 \%$ ) and was similar in both sexes; presarcopenia was identified in $21.2 \%(95 \%$ CI: $19.5 \%$ to $22.9 \%$ ) of the sample and only $3.0 \%$ (95\% CI: $2.0 \%$ to $3.5 \%$ ) of individuals had severe sarcopenia (Figure 1).

Figure 2 displays the Kaplan Meier survival estimates according to the stages of sarcopenia, demonstrating a dose-response relationship. Robust people have a higher survival probability than people with presarcopenia and sarcopenia for both sexes (Log rank test for equality of survivor functions: $p<0.0001$ ), although the $15 y$ survival probability was higher in women than in men with sarcopenia (0.66 vs 0.57 ). After 1883 person-years of follow-up (median follow-up 5.1 years), 146 new cases of sarcopenia were identified (incidence density rate $=$ 1.45 per 100 persons/years).

The Cox proportional hazards models for all-cause mortality risk according to the stages of sarcopenia are shown in Table 3. A higher risk of death was demonstrated in pre-sarcopenia and sarcopenia people when compared with robust people (hazard ratio: $\mathrm{HR}=1.83, \mathrm{p}<0.0001$ and $\mathrm{HR}=2.31, \mathrm{p}<0.0001$; respectively). After adjusting by age, sex, obesity, physical activity, number of chronic diseases, and smoking habits, the higher risk of mortality for people with pre-sarcopenia and sarcopenia when 
Table I Socio-Demographic and Health Characteristics of the Study Sample by Sex

\begin{tabular}{|c|c|c|c|c|}
\hline Variables & $\begin{array}{c}\text { Men } \\
n=756\end{array}$ & $\begin{array}{l}\text { Women } \\
n=I 555\end{array}$ & p-value & $\begin{array}{c}\text { Total } \\
n=23 \text { I I }\end{array}$ \\
\hline $\begin{aligned}{ }^{\text {a }} \text { Age (years) Mean } \pm \mathrm{SD} \\
(95 \% \mathrm{Cl})\end{aligned}$ & $\begin{array}{c}69.2 \pm 6.8 \\
(68.7-69.6)\end{array}$ & $\begin{array}{l}69.2 \pm 6.9 \\
(68.9-69.6)\end{array}$ & 0.8151 & $\begin{array}{c}69.2 \pm 6.9 \\
(68.9-69.5)\end{array}$ \\
\hline \multicolumn{5}{|l|}{${ }^{b}$ Age groups \% $(95 \% \mathrm{Cl})$} \\
\hline $\begin{array}{l}60-69.9 \text { years } \\
70-79.9 \text { years } \\
\geq 80 \text { years }\end{array}$ & $\begin{array}{c}66.0(62.5-69.4) \\
26.6(23.5-29.9) \\
7.4(5.6-9.5)\end{array}$ & $\begin{array}{c}66.8(64.3-69.1) \\
24.1(22.0-26.3) \\
9.1(7.7-10.7)\end{array}$ & 0.217 & $\begin{array}{c}66.5(64.5-68.4) \\
24.9(23.2-26.7) \\
8.6(7.5-9.8)\end{array}$ \\
\hline bLiving alone \% $(95 \% \mathrm{Cl})$ & $8.9(6.9-11.2)$ & $10.5(9.0-12.1)$ & 0.244 & $10.0(8.8-11.3)$ \\
\hline $\begin{array}{l}\text { 'Years of education Median } \\
\qquad(95 \% \mathrm{Cl})\end{array}$ & $6.0(6-6)$ & $6.0(6-6)$ & 0.3289 & $6.0(6-6)$ \\
\hline $\begin{array}{c}\text { beducation }>8 \text { years \% } \\
(95 \% \mathrm{Cl})\end{array}$ & $4 I . I(37.4-44.9)$ & $40.0(37.4-42.6)$ & 0.626 & $40.4(38.3-42.5)$ \\
\hline $\begin{array}{l}{ }^{c} \text { Number of chronic diseases } \\
\text { Median }(95 \% \mathrm{Cl})\end{array}$ & $I(I-2)$ & $2(2-2)$ & $<0.000$ I & $2(2-2)$ \\
\hline \multicolumn{5}{|c|}{${ }^{\mathrm{b}}$ Number of chronic diseases \% $(95 \% \mathrm{Cl})$} \\
\hline $\begin{array}{l}0 \\
1 \\
2 \\
\geq 3\end{array}$ & $\begin{array}{l}20.9(18.1-24.0) \\
32.3(29.0-35.7) \\
27.4(24.2-30.7) \\
19.4(16.7-22.4)\end{array}$ & $\begin{array}{l}\text { I3.4 }(|||.7-| 5.2) \\
27.5(25.3-29.8) \\
26.9(24.7-29.2) \\
32.2(29.9-34.6)\end{array}$ & $<0.000$ I & $\begin{array}{l}15.8(\mid 4.4-17.4) \\
29.1(27.2-3 \mid .0) \\
27.0(25.2-28.9) \\
28.0(26.2-29.9)\end{array}$ \\
\hline $\begin{array}{r}{ }^{\mathrm{b}} \mathrm{ADL} \text { limitation } \geq 1 \% \\
(95 \% \mathrm{Cl})\end{array}$ & $12.3(10.0-149)$ & |3.1 (II.4-14.8) & 0.611 & $12.8(11.5-14.2)$ \\
\hline $\begin{array}{r}\text { bIADL limitation } \geq 1 \% \\
(95 \% \mathrm{Cl})\end{array}$ & $30.3(27.0-33.7)$ & $25.9(23.8-28.2)$ & 0.027 & $27.4(25.5-29.2)$ \\
\hline \multicolumn{5}{|c|}{ bWeekly physical activity in last three months \% ( $95 \% \mathrm{Cl})$} \\
\hline $\begin{array}{l}0 \\
\mathrm{I}-4 \\
\geq 5\end{array}$ & $\begin{array}{c}74.8(71.5-77.9) \\
18.8(16.1-21.8) \\
6.3(4.7-8.3) \\
\end{array}$ & $\begin{array}{c}76.3(74.0-78.4) \\
20.4(18.4-22.5) \\
3.4(2.5-4.4) \\
\end{array}$ & 0.005 & $\begin{array}{c}75.8(74.0-77.5) \\
19.9(18.2-21.6) \\
4.3(3.5-5.3)\end{array}$ \\
\hline \multicolumn{5}{|l|}{ bSmoking \% (95\% Cl) } \\
\hline $\begin{array}{l}\text { Never smoker } \\
\text { Current Smoker } \\
\text { Previous smoker }\end{array}$ & $\begin{array}{c}41.3(37.6-45.0) \\
46.8(43.1-50.6) \\
11.9(9.6-14.5)\end{array}$ & $\begin{array}{c}58.8(56.3-61.3) \\
31.3(29.0-33.7) \\
9.9(8.4-11.5)\end{array}$ & $<0.000$ I & $\begin{array}{c}53.2(51.1-55.3) \\
36.3(34.3-38.3) \\
10.5(9.3-11.9)\end{array}$ \\
\hline
\end{tabular}

Notes: ${ }^{\mathrm{a} T w o}$-sample mean-comparison test; ${ }^{\mathrm{b}}$ Pearson $\mathrm{Chi}^{2}$; ${ }^{\mathrm{C}}$ Mann-Whitney test.

Abbreviations: $\mathrm{Cl}$, confidence interval; $\mathrm{SD}$, standard deviation; $\mathrm{ADL}$, activities of daily living; IADL, instrumental activities of daily living.

compared with robust people in a dose-response relationship persists for all models.

\section{Discussion}

We obtained fifteen-year survival probability stratified by stages of sarcopenia and Kaplan-Meier survival estimates by sex in a sample of 2311 older Chileans, using the consensus definition developed by the EWGSOP in
$2010^{2}$ which was previously validated in Chile by our group. ${ }^{27}$ We found that the survival rates decrease according to the stages of sarcopenia and the fifteen-year survival probability is higher in women than in men.

We identified pre-sarcopenia and sarcopenia as a risk factor for all-cause mortality, independent of obesity, number of chronic diseases, and smoking habits. Similar results with sarcopenia have been observed in several 
Table 2 Descriptive Statistics of Anthropometry, Body Composition and Physical Performance of the Study Sample by Sex

\begin{tabular}{|c|c|c|c|c|}
\hline Mean \pm SD $(95 \% \mathrm{Cl})$ & $\begin{array}{c}\text { Men } \\
n=756\end{array}$ & $\begin{array}{l}\text { Women } \\
n=\mid 555\end{array}$ & p-value ${ }^{a}$ & $\begin{array}{c}\text { Total } \\
n=23 \text { I I }\end{array}$ \\
\hline Height $(\mathrm{cm})$ & $165.3 \pm 6.7(164.8-165.7)$ & $151.1 \pm 6.3(\mid 50.8-151.4)$ & $\mathrm{P}<0.000 \mathrm{I}$ & $155.7 \pm 9.2(155.4-156.1)$ \\
\hline Weight (kg) & $74.7 \pm 13.0(73.8-75.6)$ & $66.3 \pm 12.8(65.7-67.0)$ & $\mathrm{P}<0.000 \mathrm{I}$ & $69.1 \pm 13.4(68.5-69.6)$ \\
\hline BMI $\left(\mathrm{kg} / \mathrm{m}^{2}\right)$ & $27.3 \pm 4.2(27.0-27.6)$ & $29.0 \pm 5.2(28.8-29.3)$ & $p<0.0001$ & $28.5 \pm 4.9(28.3-28.7)$ \\
\hline Knee Height (cm) & $51.5 \pm 2.7(5|.3-5| .7)$ & $46.8 \pm 2.5(46.7-46.9)$ & $\mathrm{p}<0.000 \mathrm{I}$ & $48.3 \pm 3.4(48.2-48.5)$ \\
\hline Mid-arm circumference $(\mathrm{cm})$ & $29.8 \pm 3.8(29.5-30.1)$ & $30.3 \pm 4.0(30.1-30.5)$ & $\mathrm{p}<0.000 \mathrm{I}$ & $30.1 \pm 4.0(30.0-30.3)$ \\
\hline Calf circumference $(\mathrm{cm})$ & $36.1 \pm 3.7(35.8-36.4)$ & $35.2 \pm 3.8(35.0-35.4)$ & $\mathrm{p}<0.0001$ & $35.5 \pm 3.8(35.3-35.7)$ \\
\hline Waist circumference $(\mathrm{cm})$ & $98.2 \pm 10.2(97.5-98.9)$ & $94.1 \pm 12.0(93.5-94.7)$ & $\mathrm{P}<0.000 \mathrm{I}$ & $95.4 \pm 11.6(97.5-98.9)$ \\
\hline Hip circumference $(\mathrm{cm})$ & $101.7 \pm 8.2(10.1-102.3)$ & $105.6 \pm 10.9(105.1-106.2)$ & $\mathrm{P}<0.000 \mathrm{I}$ & $104.4 \pm 10.3(103.9-104.8)$ \\
\hline $\mathrm{SMI} \leq 5.88 / 7.45 \mathrm{~kg} / \mathrm{m}^{2}$ & $47.2(43.6-50.9)$ & $37.4(35.0-39.9)$ & $p<0.0001$ & $40.6(38.6-42.7)$ \\
\hline$<25 p$ dynamometry $(<27 / / 5 \mathrm{~kg})$ & $19.3(146)(16.6-22.3)$ & $19.2(298)(17.2-21.2)$ & 0.932 & $19.2(444)(17.6-20.9)$ \\
\hline Bad physical performance & $27.8(24.6-31.1)$ & $38.9(36.5-41.4)$ & $\mathrm{p}<0.000 \mathrm{I}$ & $35.3(33.3-37.3)$ \\
\hline
\end{tabular}

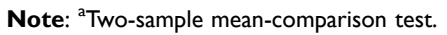

Abbreviations: $\mathrm{Cl}$, confidence interval; SD, standard deviation; BMI, body mass index; SMI, skeletal muscle mass index; 25p, 25th percentile.

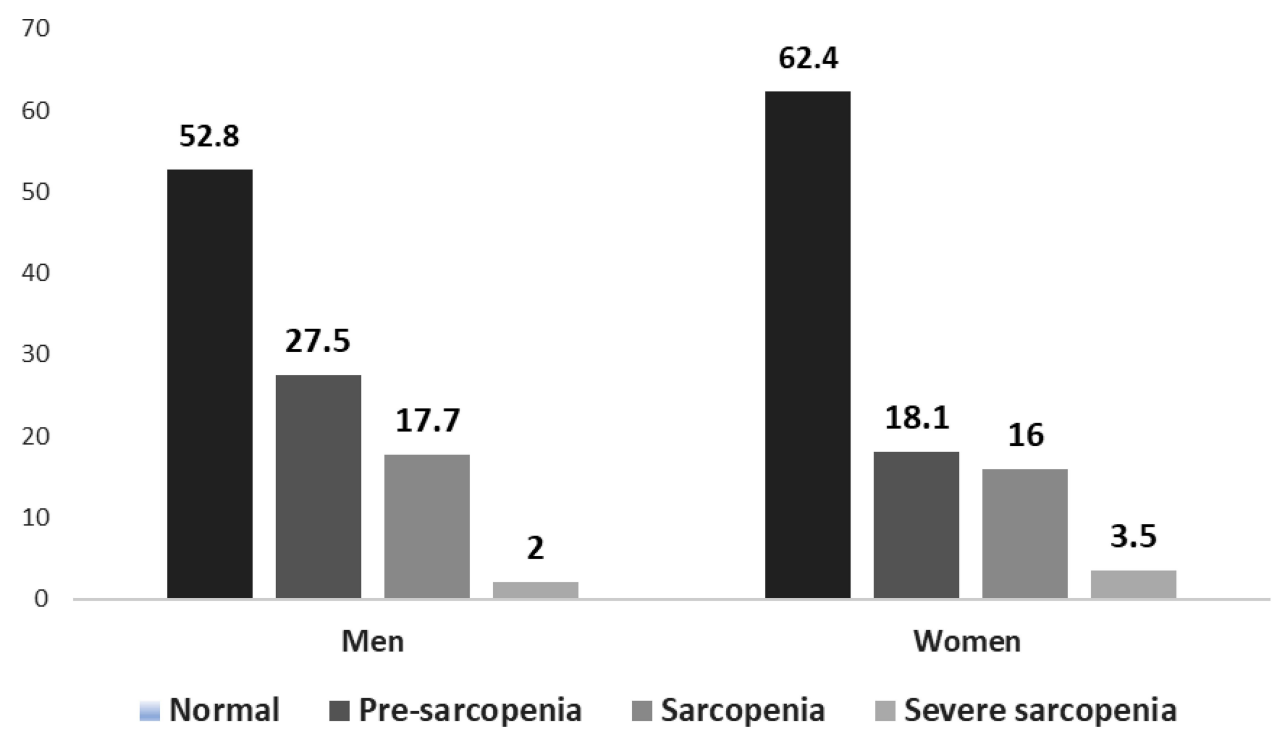

Figure I Classification by stages of sarcopenia and sex.

studies, systematic reviews and meta-analysis showing the association of sarcopenia with mortality ${ }^{19,29,30}$ but none of them have shown the association of pre-sarcopenia with mortality. A recent study in the United States found that sarcopenia is a risk factor for all-cause mortality in both sexes and for cardiovascular-specific mortality in women. ${ }^{12}$ Landi et al with a cohort of people of 80 years and older from the Aging and Longevity Study ${ }^{21}$ and Hirani et al in Australia ${ }^{20}$ reported similar results, but a study from the National Health and Nutrition Examination Survey III (1988-1994) ${ }^{19}$ found that women with sarcopenia, but not men, have an increased risk of allcause mortality, independent of obesity. Sim et al $(2019)^{30}$ have recently studied the relationship among four definitions of sarcopenia, including the European consensus, ${ }^{2}$ with long-term all-cause mortality risk in older Australian women. They found that sarcopenia was associated with increased relative hazards for all-cause mortality in older Australian women according to the AUS-POP ${ }_{\mathrm{E}}$ definition, an adaptation of European Consensus (EWGSOP1). ${ }^{30}$ To our knowledge, no other studies about the association of pre-sarcopenia and mortality have been published; however, studies of the relationship between low muscle mass and mortality are contradictory. One study in US adults demonstrated that appendicular skeletal muscle mass is inversely associated with the risk of death ${ }^{31}$ but another 

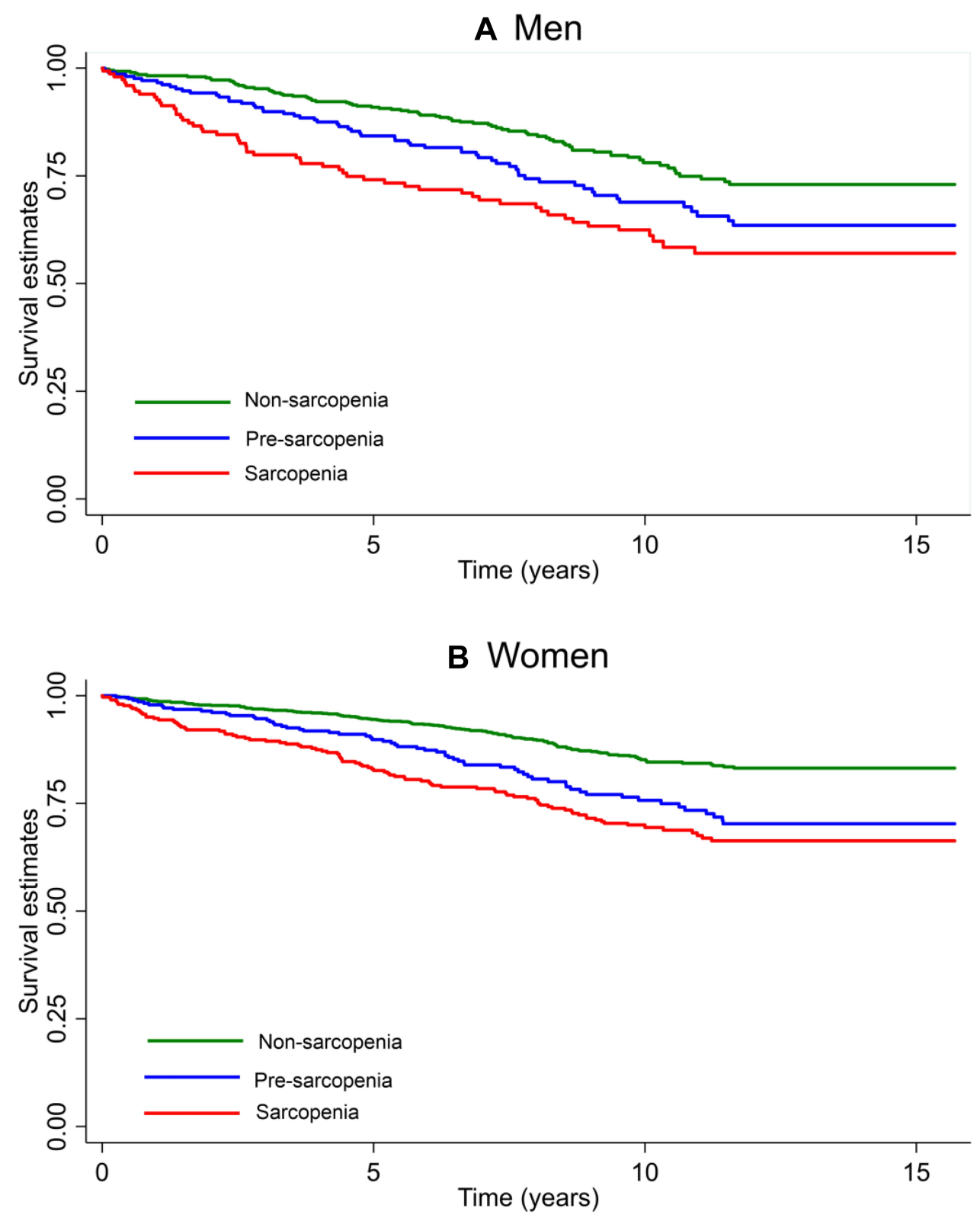

Figure 2 Kaplan-Meier survival estimates by stages of sarcopenia and sex.

Notes: Log rank test for equality of survivor functions. (A) Men: $\operatorname{chi}^{2}(I)=19.91 ; p<0.0001$. (B) Women: $\operatorname{chi}^{2}(I)=47.15 ; p<0.000 I$

study done in the US population also showed the association only for low muscle strength. ${ }^{32}$

Using the model validated previously by our group, ${ }^{24}$ we found a $19.6 \%$ prevalence of sarcopenia among community-dwelling older adults, similar to the prevalence obtained in a sample of 1006 older people with DEXA $(19.1 \%) .{ }^{15}$ Pre-sarcopenia was identified in $21.2 \%$ of the sample, a figure like that observed in a previous study (18.4\%), using the same anthropometric equation for calculating appendicular skeletal muscle mass. ${ }^{26}$ A similar prevalence of pre-sarcopenia was found in community-dwelling Japanese older adults $(21.8 \%) .{ }^{33}$ The studies on the prevalence of sarcopenia in older people in Latin America do not report the prevalence of pre-sarcopenia.

Most of the studies have been done with the EWGSOP1 criteria, in part due to the fact that the EWGSOP2 algorithm was published at the end of 2018. Several reports generated with communitydwelling older adults demonstrate that the EWGSOP2 algorithm produces a lower estimate of sarcopenia prevalence $^{34,35}$ than EWGSOP1 and notes that only 
Table 3 Proportional Hazard Models for I5y Mortality Risk According to Sarcopenia

\begin{tabular}{|c|c|c|c|c|c|}
\hline Variables & Model I & Model 2 & Model 3 & Model 4 & Model 5 \\
\hline & $\begin{array}{c}\text { HR } \\
95 \% \mathrm{Cl}\end{array}$ & $\begin{array}{c}\text { HR } \\
95 \% \mathrm{Cl}\end{array}$ & $\begin{array}{c}\text { HR } \\
95 \% \mathrm{Cl}\end{array}$ & $\begin{array}{c}\text { HR } \\
95 \% \mathrm{Cl}\end{array}$ & $\begin{array}{c}\text { HR } \\
95 \% \mathrm{Cl}\end{array}$ \\
\hline Pre-sarcopenia & $\begin{array}{c}1.83 \\
1.46-2.28\end{array}$ & $\begin{array}{c}1.33 \\
1.06-1.67\end{array}$ & $\begin{array}{c}1.33 \\
1.02-1.74\end{array}$ & $\begin{array}{c}1.35 \\
1.03-1.78\end{array}$ & $\begin{array}{c}1.35 \\
1.03-1.78\end{array}$ \\
\hline Sarcopenia & $\begin{array}{c}2.3 \mathrm{I} \\
1.87-2.86\end{array}$ & $\begin{array}{c}1.4 \mid \\
1.13-1.76\end{array}$ & $\begin{array}{c}1.42 \\
1.08-1.85\end{array}$ & $\begin{array}{c}1.41 \\
1.08-1.84\end{array}$ & $\begin{array}{c}1.39 \\
1.07-1.82\end{array}$ \\
\hline \multicolumn{6}{|l|}{ Groups of age } \\
\hline 70-79 years & & $\begin{array}{c}3.42 \\
2.77-4.24\end{array}$ & $\begin{array}{c}3.49 \\
2.81-4.33\end{array}$ & $\begin{array}{c}3.50 \\
2.81-4.35\end{array}$ & $\begin{array}{c}3.35 \\
2.70-4.18\end{array}$ \\
\hline $80+$ years & & $\begin{array}{c}8.07 \\
6.30-10.35\end{array}$ & $\begin{array}{c}8.06 \\
6.23-10.42\end{array}$ & $\begin{array}{c}7.95 \\
6.13-10.30\end{array}$ & $\begin{array}{c}7.65 \\
5.90-9.93\end{array}$ \\
\hline Female & & $\begin{array}{c}0.61 \\
0.50-0.73\end{array}$ & $\begin{array}{c}0.62 \\
0.51-0.75\end{array}$ & $\begin{array}{c}0.62 \\
0.51-0.75\end{array}$ & $\begin{array}{c}0.62 \\
0.51-0.76\end{array}$ \\
\hline Obese & & & $\begin{array}{c}1.06 \\
0.82-1.37\end{array}$ & $\begin{array}{c}1.04 \\
0.80-1.35\end{array}$ & $\begin{array}{c}1.02 \\
0.79-1.33\end{array}$ \\
\hline \multicolumn{6}{|l|}{ Physical activity } \\
\hline $\mathrm{I}-4$ & & & & $\begin{array}{c}0.85 \\
0.67-1.08\end{array}$ & $\begin{array}{c}0.85 \\
0.67-1.08\end{array}$ \\
\hline $5+$ & & & & $\begin{array}{c}0.09 \\
0.01-0.63\end{array}$ & $\begin{array}{c}0.09 \\
0.01-0.62\end{array}$ \\
\hline \multicolumn{6}{|c|}{ Number of chronic diseases } \\
\hline I & & & & $\begin{array}{c}0.93 \\
0.70-1.24\end{array}$ & $\begin{array}{c}0.93 \\
0.70-1.24\end{array}$ \\
\hline 2 & & & & $\begin{array}{c}0.97 \\
0.72-1.30\end{array}$ & $\begin{array}{c}0.98 \\
0.73-1.32\end{array}$ \\
\hline $3+$ & & & & $\begin{array}{c}0.93 \\
0.69-1.25\end{array}$ & $\begin{array}{c}0.94 \\
0.70-1.27\end{array}$ \\
\hline Current Smoker & & & & & $\begin{array}{c}1.22 \\
0.90-1.64\end{array}$ \\
\hline Past Smoker & & & & & $\begin{array}{c}1.12 \\
0.91-1.37\end{array}$ \\
\hline
\end{tabular}

Notes: Reference category of independent variables: non-sarcopenia; 60-69 years; men; non-obese; sedentary; 0 chronic disease; never smoker. Abbreviations: $\mathrm{HR}$, hazard ratio; $\mathrm{Cl}$, confidence interval.

severe sarcopenia produces adverse outcomes compared to sarcopenia defined with EWGSOP1. We decided to use EWGSOP1 considering the severe consequences of sarcopenia and the need to identify most people at risk. The relevance of the present study lies in the inclusion of pre-sarcopenia as an all-cause mortality risk, thus demonstrating that pre-sarcopenia detection is very important to avoid preventable deaths.
The main limitation of this study is the use of TUG to measure physical performance when gait speed was not available. However, the prevalence of sarcopenia estimated in this sample of 2311 older adults was almost the same as prevalence obtained in a sample of 1006 people based on DXA scan measurements, three-meter walk speed, and grip-strength $(19.1 \%) .{ }^{15}$ The most important strength of the present study is the long 
follow-up and the large sample of community-dwelling Latin American older people.

\section{Conclusion}

These results confirm a higher risk of all-cause mortality for older adults with pre-sarcopenia and sarcopenia compared to non-sarcopenic individuals. A dose-response was observed with survival rates, where subjects without sarcopenia showed better rates than those with increasingly severe sarcopenia. Considering the identification of pre-sarcopenia as a risk factor for lower survival, its identification in patients could allow interventions earlier in the natural course of the disease. Although the new EWGSOP algorithm did not include its identification, pre-sarcopenia detection is very important to avoid preventable deaths. Future studies are needed to validate the inclusion of pre-sarcopenia as one of the diagnostic algorithm outcomes.

\section{Ethics}

This study was conducted in accordance with the Declaration of Helsinki. The study and the consent form were approved by the ethics committee of the Institute of Nutrition and Food Technology. All subjects signed a consent form before any procedure was undertaken.

\section{Acknowledgment}

This research was supported by the Chilean National Fund for Scientific and Technological Development (Fondecyt grant 1130947 and Fondef grant 15I10053).

\section{Disclosure}

The authors report no conflicts of interest in this work.

\section{References}

1. Fielding RA, Vellas B, Evans WJ, et al. Sarcopenia: an undiagnosed condition in older adults. Current consensus definition: prevalence, etiology, and consequences. International Working Group on Sarcopenia. J Am Med Dir Assoc. 2011;12(4):249-256. doi:10.1016/ j.jamda.2011.01.003

2. Cruz-Jentoft AJ, Baeyens JP, Bauer JM, et al. Sarcopenia: European consensus on definition and diagnosis: report of the European Working Group on Sarcopenia in Older People. Age Ageing. 2010;39 (4):412-423. doi:10.1093/ageing/afq034

3. Delmonico MJ, Harris TB, Lee J-S, et al. Alternative definitions of sarcopenia, lower extremity performance, and functional impairment with aging in older men and women. J Am Geriatr Soc. 2007;55 (5):769-774. doi:10.1111/j.1532-5415.2007.01140.x

4. Landi F, Liperoti R, Russo A, et al. Sarcopenia as a risk factor for falls in elderly individuals: results from the ilSIRENTE study. Clin Nutr. 2012;31(5):652-658. doi:10.1016/j.clnu.2012.02.007
5. Lauretani F, Russo CR, Bandinelli S, et al. Age-associated changes in skeletal muscles and their effect on mobility: an operational diagnosis of sarcopenia. J Appl Physiol. 2003;95(5):1851-1860. doi:10.1152/ japplphysiol.00246.2003

6. Albala C, Sánchez H, Lera L, Angel B, Fuentes A, Arroyo P. Sarcopenia is more important than vitamin D deficiency as determinant of osteoporosis in Chilean elders. Osteoporos Int. 2012;23(Suppl 2):S343-S344.

7. Serra Rexach JA. [Clinical consequences of sarcopenia]. Nutr Hosp. 2006;21 Suppl 3(3):46-50. Spanish.

8. Guralnik JM, Ferrucci L, Simonsick EM, Salive ME, Wallace RB. Lower-extremity function in persons over the age of 70 years as a predictor of subsequent disability. $N$ Engl J Med. 1995;332 (9):556-561. doi:10.1056/NEJM199503023320902

9. Cruz-Jentoft AJ, Landi F, Topinková E, Michel J-P. Understanding sarcopenia as a geriatric syndrome. Curr Opin Clin Nutr Metab Care. 2010;13(1):1-7. doi:10.1097/MCO.0b013e328333c1c1

10. Landi F, Cruz-Jentoft AJ, Liperoti R, et al. Sarcopenia and mortality risk in frail older persons aged 80 years and older: results from ilSIRENTE study. Age Ageing. 2013;42(2):203-209. doi:10.1093/ ageing/afs 194

11. Bunout D, de la Maza MP, Barrera G, Leiva L, Hirsch S. Association between sarcopenia and mortality in healthy older people. Australas J Ageing. 2011;30(2):89-92. doi:10.1111/j.1741-6612.2010.00448.x

12. Brown JC, Harhay MO, Harhay MN. Sarcopenia and mortality among a population-based sample of community-dwelling older adults. J Cachexia Sarcopenia Muscle. 2015;7(3):290-298. doi:10.1002/jcsm. 12073

13. Cruz-Jentoft AJ, Bahat G, Bauer J, et al. Sarcopenia: revised European consensus on definition and diagnosis. Age Ageing. 2018. doi:10.1093/ageing/afy169

14. WHO. World Population Report; 2020.

15. Lera L, Albala C, Sánchez H, et al. Prevalence of sarcopenia in community-dwelling Chilean elders according to an adapted version of the European Working Group on Sarcopenia in Older People (EWGSOP) Criteria. $J$ Frailty Aging. 2017;6(1):12-17. doi:10.14283/jfa.2016.117

16. Alexandre TDS, Duarte YADO, Santos JLF, Wong R, Lebrao ML. Sarcopenia according to the European Working Group on Sarcopenia in Older People (EWGSOP) versus dynapenia as a risk factor for mortality in the elderly. $J$ Nutr Health Aging. 2014;18(8):751-756. doi:10.1007/s12603-014-0540-2

17. Samper-Ternent R, Reyes-Ortiz C, Ottenbacher KJ, Cano CA. Frailty and sarcopenia in Bogotá: results from the SABE Bogotá Study. Aging Clin Exp Res. 2016;1-8. doi:10.1007/s40520-016-0561-2

18. Arango-Lopera VE, Arroyo P, Gutiérrez-Robledo LM, Pérez-Zepeda MU. Prevalence of sarcopenia in Mexico City. Eur Geriatr Med. 2012;3(3):157-160. doi:10.1016/j.eurger.2011.12.001

19. Batsis JA, Mackenzie TA, Barre LK. Sarcopenia, sarcopenic obesity and mortality in older adults: results from the national health and nutrition examination survey III. Eur J Clin Nutr. 2014;68(9):1-7. doi:10.1038/ejen.2014.117

20. Hirani V, Blyth F, Naganathan V, et al. Sarcopenia is associated with incident disability, institutionalization, and mortality in community-dwelling older men: the concord health and ageing in men project. J Am Med Dir Assoc. 2015;16(7):607-613. doi:10.1016/ j.jamda.2015.02.006

21. Landi F, Calvani R, Tosato M, et al. Impact of physical function impairment and multimorbidity on mortality among community-living older persons with sarcopaenia: results from the ilSIRENTE prospective cohort study. BMJ Open. 2016;6(7):e008281. doi:10.1136/bmjopen-2015-008281

22. Liu P, Hao Q, Hai S, Wang H, Cao L, Dong B. Sarcopenia as a predictor of all-cause mortality among community-dwelling older people: a systematic review and meta-analysis. Maturitas. 2017;103:16-22. doi:10.1016/j.maturitas.2017.04.007 
23. Albala C, Sánchez H, Lera L, Angel B, Cea X. [Socioeconomic inequalities in active life expectancy and disability related to obesity among older people]. Rev Med Chil. 2011;139(10):1276-1285. Spanish. doi:10.4067/S0034-98872011001000005

24. Lera L, Albala C, Ángel B, et al. [Anthropometric model for the prediction of appendicular skeletal muscle mass in Chilean older adults]. Nutr Hosp. 2014;29(3):611-617. Spanish. doi:10.3305/ nh.2014.29.3.7062

25. Lang IA, Llewellyn DJ, Alexander K, Melzer D. Obesity, physical function, and mortality in older adults. $J$ Am Geriatr Soc. 2008;56 (8):1474-1478. doi:10.1111/j.1532-5415.2008.01813.x

26. Lera L, Angel B, Márquez C, Saguez R, Albala C. Software for the diagnosis of sarcopenia in community-dwelling older adults: design and Validation Study. JMIR Med Informatics. 2020;8(4):e13657. doi: $10.2196 / 13657$

27. Lera L, Ángel B, Sánchez H, et al. [Validation of cut points of skeletal muscle mass index for identifying sarcopenia in Chilean older people]. Nutr Hosp. 2015;31(3):1187-1197. Spanish. doi:10.3305/nh.2015.31.3.8054

28. Lera L, Albala C, Leyton B, et al. Reference values of hand-grip dynamometry and the relationship between low strength and mortality in older Chileans. Clin Interv Aging. 2018;13:317-324. doi:10.2147/CIA.S152946

29. Yuki A, Ando F, Otsuka R, Shimokata H. Sarcopenia based on the Asian Working Group for Sarcopenia criteria and all-cause mortality risk in older Japanese adults. Geriatr Gerontol Int. 2017;17 (10):1642-1647. doi:10.1111/ggi.12946
30. Sim M, Prince RL, Scott D, et al. Sarcopenia definitions and their associations with mortality in older Australian women. J Am Med Dir Assoc. 2019;20(1):76-82.e2. doi:10.1016/j.jamda.2018.10.016

31. Abramowitz MK, Hall CB, Amodu A, Sharma D, Androga L, Hawkins M. Muscle mass, BMI, and mortality among adults in the United States: a population-based cohort study. PLoS One. 2018;13 (4). doi:10.1371/journal.pone.0194697

32. Li R, Xia J, Zhang X, et al. Associations of muscle mass and strength with all-cause mortality among US Older Adults. Med Sci Sports Exerc. 2018;50(3):458-467. doi:10.1249/MSS.0000000000001448

33. Kobayashi K, Ando K, Tsushima M, et al. Predictors of presarcopenia in community-dwelling older adults: a 5-year longitudinal study. Mod Rheumatol. 2019;29(6):1053-1058. doi:10.1080/ 14397595.2018.1551171

34. Petermann-Rocha F, Chen M, Gray SR, Ho FK, Pell JP, CelisMorales C. New versus old guidelines for sarcopenia classification: what is the impact on prevalence and health outcomes? Age Ageing. 2020;49(2):300-304. doi:10.1093/ageing/afz126

35. Locquet $M$, Beaudart $C$, Petermans J, Reginster J-Y, Bruyère $O$. EWGSOP2 Versus EWGSOP1: impact on the prevalence of sarcopenia and its major health consequences. J Am Med Dir Assoc. 2019;20 (3):384-385. doi:10.1016/j.jamda.2018.11.027
Clinical Interventions in Aging

\section{Publish your work in this journal}

Clinical Interventions in Aging is an international, peer-reviewed journal focusing on evidence-based reports on the value or lack thereof of treatments intended to prevent or delay the onset of maladaptive correlates of aging in human beings. This journal is indexed on PubMed Central, MedLine, CAS, Scopus and the Elsevier

\section{Dovepress}

Bibliographic databases. The manuscript management system is completely online and includes a very quick and fair peer-review system, which is all easy to use. Visit http://www.dovepress.com/ testimonials.php to read real quotes from published authors. 